\title{
PENGEMBANGAN DAN PENATAAN REKREASI WISATA ALAM AIR TERJUN TUKAD CEPUNG
}

\author{
I Putu Widiarsana \\ Program Studi Arsitektur, Fakultas Teknik, Universitas Dwijendra \\ widi.putu@gmail.com \\ I Ketut Adhimastra \\ Program Studi Arsitektur, Fakultas Teknik, Universitas Dwijendra \\ adhimastra2301@yahoo.com \\ I Nyoman Gde Suardana \\ Program Studi Arsitektur, Fakultas Teknik, Universitas Dwijendra \\ suarbali@yahoo.com
}

\begin{abstract}
Abstrak
Rekreasi Wisata Alam Air Terjun Tukad Cepung merupakan destinasi wisata alam yang dalam beberapa tahun terakhir dari segi kunjungan mengalami peningkatan yang sangat pesat, pada tahun 2016 jumlah kunjungan mencapai 18,754 wisatawan dan tahun 2017 mencapai 31,636 wisatawan. Namun perkembangan tersebut tidak diimbangi dengan peningkatan fasilitas yang ada, kondisi fasilitas saat ini tidak tertata dengan baik dan masih sangat minim untuk dapat mengimbangi jumlah kunjungan tersebut, sehingga pengembangan dan penataan fasilitas pada Rekreasi Wisata Alam Air Terjun Tukad Cepung sangat diperlukan.

Dari uraian di atas dapat diambil rumusan masalah sebagai berikut. Bagaimana konsep Pengembangan dan Penataan Rekreasi Wisata Alam Air Terjun Tukad Cepung? Fasilitas apa saja yang dibutuhkan pada Rekreasi Wisata Alam Air Terjun Tukad Cepung?

Dalam Pengembangan dan Penataan Rekreasi Wisata Alam Air Terjun Tukad Cepung, konsep dasar yang diterapkan pada Pengembangan dan Penataan Rekreasi Wisata Alam Air Terjun Tukad Cepung adalah Rekreatif dan Nyaman. Sedangkan tema yang akan diterapkan yaitu Green Architecture, Green Architecture atau Arsitektur Hijau adalah arsitektur yang minim mengonsumsi sumber daya alam, ternasuk energi, air, dan material, serta tidak menimbulkan dampak negatif bagi lingkungan. Tema ini ditentukan berdasarkan beberapa pendekatan yaitu: pendekatan fungsional, pendekatan iklim dan lingkungan dan pendekatan latar belakang budaya.

Konsep Pengembangan dan Penaataan Rekreasi Wisata Alam Air Terjun Tukad Cepung terdiri dari konsep zoning, bentuk dan massa bangunan, sirkulasi dan parkir, jalur pejalan kaki, ruang terbuka dan penanda.
\end{abstract}

Kata Kunci : Pengembangan, Penataan, Fasilitas, Objek Wisata, Air Terjun Tukad Cepung.

\begin{abstract}
Recreation Natural Tourism Tukad Cepung Waterfall is a natural tourist destination which in recent years in terms of visits has increased very rapidly, in 2016 the number of visits reached 18,754 tourists and in 2017 reached 31,636 tourists. However, these developments are not matched by an increase in existing facilities, the current condition of the facilities is not well organized and is still very minimal to be able to compensate for the number of visits, so that the development and arrangement of facilities in the Recreation of Natural Tourism Tukad Cepung Waterfall is very necessary.

From the description above, the formulation of the problem can be taken as follows. What is the concept of the Development and Arrangement of Tukad Cepung Waterfall Natural Tourism Recreation? What facilities are needed for Tukad Cepung Waterfall Natural Tourism Recreation? In the Development and Arrangement of Tukad Cepung Waterfall Natural Tourism Recreation, the basic concepts applied to the Development and Structuring of Recreation for Tukad Cepung Waterfall Natural Recreation are Recreational and Comfortable. While the theme that will be applied is Green Architecture, Green Architecture or Green Architecture is an architecture that minimizes the consumption of natural resources, including energy, water, and materials, and does not cause
\end{abstract}


negative impacts on the environment. This theme is determined based on several approaches: functional approach, climate and environmental approach and cultural background approach. Concept of Development and Arrangement of Recreation Tukad Cepung Waterfall Natural Tourism consists of the concept of zoning, building from and massing, circulation and parking, pedestrian ways, open spaces and signage.

Keywords: Development and Arrangement, Tourism Object Facilities, Tukad Cepung Waterfall.

\section{PENDAHULUAN}

\subsection{Latar Belakang}

Objek Wisata Tukad Cepung merupakan salah satu destinasi wisata yang berada di Kabupaten Bangli, tepatnya di Desa Pakraman Penida Kelod, Desa Tembuku, Kecamatan Tembuku yang berjarak kira-kira 55 menit dari Kota Denpasar dalam kondisi lalu lintas normal dan 15 menit dari Kota Bangli.

Dalam beberapa tahun terakhir Objek Wisata Air Terjun Tukad Cepung begitu populer dikalangan wisatawan, hal ini tidak lepas dari perkembangan teknologi informasi yang semakin pesat dan beberapa hal lain yang membuat wisatawan semakin hari semakin ramai berkunjung adalah karena keberadaan Objek Wisata ini cukup mudah untuk dijangkau. Air Terjun Tukad Cepung memiliki keunikan tersendiri yaitu, dalam perjalanan menuju air terjun wisatawan akan melewati dinding bebatuan alami yang ditumbuhi lumut hijau dan ketika semakin dekat dengan air terjun wisatawan harus melwati celah-celah bebatuan yang sangat sempit, jika jam bekunjungnya tepat, di atas bebatuan ini adalah surganya bagi wisatawan yang suka berfoto selain di objek utama yaitu air terjun. hal ini membuat Objek Wisata Air Terjun Tukad Cepung berbeda dengan obyek wisata air terjun pada umumnya dan keunikan lainnya adalah Air Terjun Tukad Cepung hanya bisa dilihat jika kita berada tepat 10-20 meter di depannya, ini disebabkan karena letaknya yang berada di bawah permukaan tanah sehingga menyerupai goa, inilah yang membuat tempat ini dinamakan tukad cepung, selain letaknya paling bawah juga memiliki kedalaman paling dalam yaitu 15 meter.

Dilihat dari data jumlah kunjungan wisatawan yang berkunjung ke Objek Wisata Air Terjun Tukad Cepung, setiap tahunnya terus mengalami peningkatan dimana pada tahun 2016 jumlah pengunjung mencapai 18,754 kemudian pada tahun 2017 jumlah kunjungan wisatawan mengalami peningkatan menjadi 31,636 dan diawal tahun 2018 periode Januari-Februari sudah mencapai 5,747 seperti yang ditunjukan pada tabel 1

Tabel 1. Jumlah kunjungan wisatawan ke Objek Wisata di Bangli 


\begin{tabular}{llrrrr}
\hline No & Nama DTW & $\mathbf{2 0 1 6}$ & $\mathbf{2 0 1 7}$ & $\mathbf{2 0 1 8}$ & Jumlah \\
& & 492,201 & 542,724 & 58,764 & $1,093,689$ \\
\hline 1 & Batur & 123,133 & 209,267 & 29,587 & 361,987 \\
2 & Penglipuran & 18,561 & 25,953 & 3,326 & 47,840 \\
3 & Kehen & 1,388 & 1,012 & 61 & 2,461 \\
4 & Penulisan & 12,628 & 11,866 & 1,252 & 25,746 \\
5 & Trunyan & 46,851 & 0 & 0 & 46,851 \\
6 & P3GB & 18,754 & 31,636 & 5,747 & 56,137 \\
7 & Air Terjun Tukad Cepung & & & & \\
\end{tabular}

Sumber : Dinas Pariwisata Kabupaten Bangli, Buku Tamu Objek Wisata Air Terjun Tukad Cepung (2016-2018)

Berdasarkan data di atas dapat dilihat kunjungan wisatawan ke Objek Wisata Air Terjun Tukad Cepung setiap tahunnya terus mengalami peningkatan seperti yang ditunjukan pada tabel 1.1 yaitu, pada tahun 2016-2017 mengalami peningkatan sebesar 40,71\%. Sedangkan jumlah kunjungan wisatawan yang berkunjung ke Kabupaten Bangli adalah 1,580,819 seperti yang ditunjukan pada tabel 2

Tabel 2 Jumlah kunjungan wisaatawan ke Kabupaten Bangli

\begin{tabular}{llc}
\hline No & Tahun & Jumlah \\
\hline 1 & Januari-Desember 2016 & 694,762 \\
2 & Januari-Desember 2017 & 790,822 \\
3 & Januari-Februari 2018 & 95.235 \\
& Total Jumlah Kunjungan & $\mathbf{1 , 5 8 0 , 8 1 9}$ \\
\hline
\end{tabular}

Sumber : Dinas Pariwisata Kabupaten Bangli (2016-2018)

Dari data kunjungan tersebut jika dipersentasekan wisatawan yang berkunjung ke Objek Wisata Air Terjun Tukad Cepung adalah sekitar 3,55\% dari jumlah kunjungan wisatawan ke Kabupaten Bangli. Dilihat dari jumlah kunjungan wisatawan ke Kabupaten Bangli yaitu sebesar 1,580,819 maka kunjungan wisatawan ke Objek Wisata Air Terjun Tukad Cepung yang sebesar 3,55\% adalah hal yang sangat realistis.

Dilihat dari jumlah kunjungan wisatawan yang bekunjung ke Bali jumlah kunjungan wisatawan ke Kabupaten Bangli adalah yang paling rendah dibadingkan kabupaten lainnya di Bali, seperti yang ditunjukan pada tabel 3 
Tabel 3. Jumlah Kujungan Wisatawan ke Bali

\begin{tabular}{llc}
\hline No & Tahun & Jumlah \\
\hline 1 & Januari-Desember 2016 & $4,927,937$ \\
2 & Januari-Desember 2017 & $5,697,739$ \\
3 & Januari-Februari 2018 & 810,488 \\
& Total Jumlah Kunjungan & $\mathbf{1 1 , 4 3 6 , 1 6 4}$
\end{tabular}

Sumber : http://www.disparda.baliprov.go.id/id/Statistik4 (12 April 2018)

Dilihat dari kunjungan wisatawan ke Objek Wisata Tukad Cepung seperti yang ditunjukan pada tabel 1 peningkatan jumlah kunjungan wisatawan mencapai $40,71 \%$. Meskipun hanya 3,55\% dari jumlah kunjungan wisatawan ke Kabupaten Bangli, namun pekembangan jumlah kunjungan per-tahunya terus mengalami peningkatan, sehingga perlu adanya peningkatan faslitas pada Objek Wisata Air Terjun Tukad Cepung, agar dapat mendukung aktivitas wisatawan.

Adapun fasilitas yang tersedia di Objek Wisata Air Terjun Tukad Cepung seperti yang ditunjukan pada tabel 4

Tabel 4. Kondisi Fasilitas Objek Wisata Air Terjun Tukad Cepung.

\begin{tabular}{llll}
\hline No & Fasilitas & Kapasitas & Keterangan \\
\hline 1 & Parkir & $\begin{array}{l}7 \text { unit mobil dan 15 } \\
\text { unit kendaraan roda } 2\end{array}$ & Kurang memadai \\
2 & Toilet (areal atas) & 2 unit & Kurang memadai \\
& Toilet (areal bawah) & 1 unit & Rusak \\
3 & Ruang ganti & 0 & Tidak ada \\
4 & Gazebo 1 unit & 10 orang & Kurang memadai \\
5 & Loket & 4 orang & Baik \\
6 & Akses jalan & - & Baik \\
\hline
\end{tabular}

Sumber : Inventaris Objek Wisata Tukad Cepung (2018)

Berdasarkan data seperti yang ditunjukan pada tabel 4 tempat parkir di Objek Wisata Air Terjun Tukad Cepung, saat ini masih menggunakan areal setra yang hanya dapat menampung sekitar 7 unit mobil dan 15 unit kendaraan roda dua, sementara jumlah wisatawan yang berkunjung menggunakan mobil mencapai 30-40 unit per hari dan 
kendaraan roda dua 20-35 unit per hari sehingga bisa dibilang kondisi parkiran di objek wisata air terjun tukad cepung uperload dan harus menggunakan badan jalan untuk memenuhi kebutuhan parkir tersebut, begitu juga dengan fasilitas penunjang lainnya seperti toilet yang saat ini jumlahnya hanya dua unit tentu saja sangat jauh dari cukup untuk mengimbangi jumlah kunjungan wisatawan.

Ditinjau dari kondisi site guna meningkatkan jumlah kunjungan wisatawan, Objek Wisata Air Terjun Tukad Cepung memiliki potensi wisata lain yang layak dikembangkan sebagai objek penunjang yaitu :

1. Pengelukatan.

Pengelukatan ini dikenal dengan nama penglukatan nawa ratna. Pengelukatan ini ramai dikunjungi pada rainan purnama biasanya mereka berkunjung ke pengelukatan nawa ratna dengan tujuan pembersihan diri, tapi banyak juga yang datang dengan tujuan spiritual tertentu, karena menurut mereka aura ditempat ini bagus untuk peningkatan spiritual maupun meditasi. Keberadaan pengelukatan ini berdampingan dengan air terjun, jalan menuju pengelukatan nawa ratna ini satu jalur dengan air terjun, sehingga sebelum sampai di air terjun kita akan melihat petunjuk yang akan mengarahkan kita ke pengelukatan ataupun ke air terjun.

2. Wisata Agro.

Wisata agro memanfaatkan perkebuan dan sawah milik masyrakat disepanjang jalan menuju air terjun, adapun tanaman yang ada di perkebunan tersebut adalah pohon jeruk, bunga mitir, pohon durian, pohon kelapa dan untuk di sawah tanamannya menyesuaikan berdasarkan pembagian air, jika di sawah tersebut mendapat giliran pembagian air dari subak maka yang ditanam adalah padi dan jika tidak maka tanamannya bisa bunga atau ubi jalar.

3. Camping Camp dan outbond.

Camping Camp dan outbond memanfaatkan area lahan milik dinas PU kabupaten bangli dimana sistem dari penggunaan lahan tersebut adalah hak guna pakai, lahan tersebut saat ini dimanfaatkan oleh masyarakat untuk ditanami rumput pakan ternak, dan pohon kelapa. Sehingga sangat memungkinkan untuk dikembangkan sebagai Camping Camp dan outbond.

Berdasarkan potensi dan fasilitas yang ada pada Objek Wisata Air Terjun Tukad Cepung, untuk meningkatkan kualitas pelayanan dan mendongkrak jumlah kunjungan wisatawan, maka Objek Wisata Air Terjun Tukad Cepung perlu untuk dikembangkan dan ditata agar dapat meningkatkan jumlah kunjungan serta mampu memberikan rasa nyaman bagi wisatawan yang berkunjunga ke Objek Wisata Air Terjun Tukad Cepung.

\section{METODE}

Metode pengumpulan data yang digunakan pada Pengembangan dan Penataan Rekreasi Wisata Alam Air Terjun Tukad Cepung adalah metode pengumpulan data kualitatif, dilihat dari sumbernya maka penelitian ini menggunakan data primer dan 
sekunder, data primer yakni keseluruhan data yang bersumber dari hasil wawancara, observasi dan dokumentasi. Sedangkan data sekundernya adalah data yang bersumber dari lembaga yakni Dinas Pariwisata Daerah Bali, DISBUDPAR Kabupaten Bangli dan Pemerintah Desa Tembuku.

1. Data Primer

a. Wawancara

Wawancara merupakan pengambilan data secara lisan atau langsung dengan sumberdatanya. Dalam laporan ini narasumbernya adalah Ketua Pengelola Objek Wisata Tukad Cepung, wakil pengelola dan masyarakat.

b. Observasi

Observasi merupakan pengamatan langsung yang dilakukan untuk mengetahui kondisi eksisting, keadaan fisik dan lain-lainnya yang didapatkan untuk mendukung kelengkapan data.

c. Dokumentasi

Dokumentasi merupakan pengambilan data melalui dekumen tertulis maupun elektronik yang diperoleh baik dari Dinas Pariwisata Daerah Bali, DISBUDPAR Kabupaten Bangli dan Pemerintah Desa Tembuku, Pengelola Objek Wisata Air Terjun Tukad Cepung dan lain-lain.

2. Data Sekunder

Data sekunder dalam laporan ini adalah yang bersumber dari Lembaga-lembaga terkait yakni Dinas Pariwisata Daerah Bali, DISBUDPAR Kabupaten Bangli dan Pemerintah Desa Tembuku.

\section{HASIL DAN PEMBAHASAN}

\subsection{Lokasi Objek Pengembangan dan Penataan Rekreasi Wisata Alam Air Terjun Tukad Cepung}

Objek Wisata Air Terjun Tukad Cepung berada di Desa Pakraman Penida Kelod, Desa Tembuku, Kecamatan Tembuku, Kabupaten Bangli.

Untuk menunju lokasi Objek Wisata Air Terjun Tukad Cepung jika dari Denpasar dapat melalui jalan by pass Prof. Dr. Ida Bagus Mantra, kemudian ke utara $\pm 12 \mathrm{~km}$ melaluai Desa Banjarangkan.

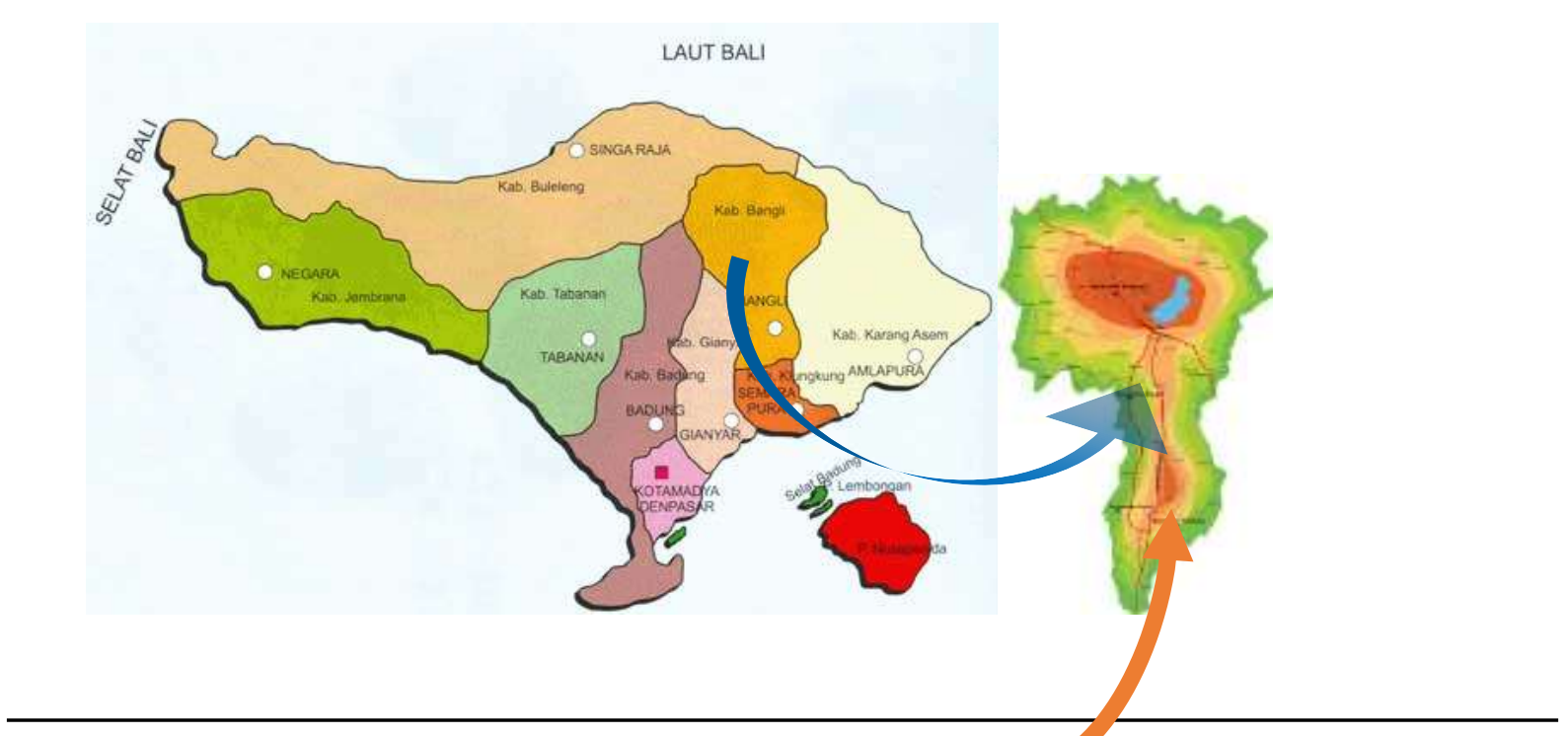




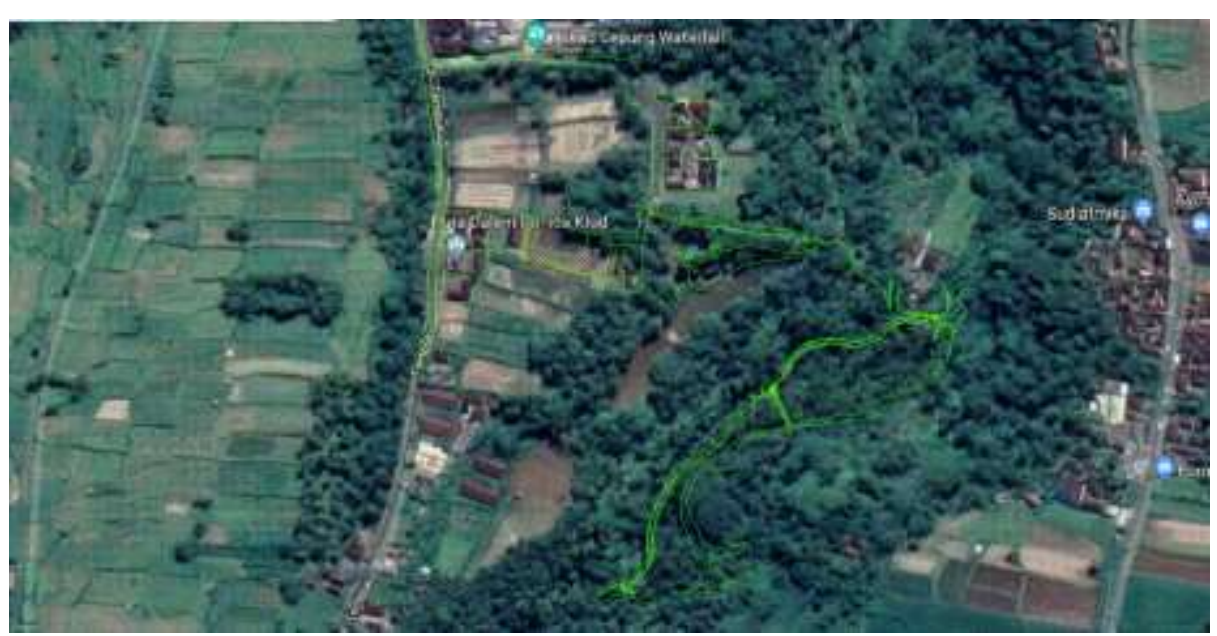

Gambar 1. Peta Lokasi Air Terjun Tukad Cepung (Sumber :https://www.googlemaps.co.id diakses tanggal 06/04/2018)

\subsection{Kondisi Fisik}

Kondisi fisik Objek Wisata Air Terjun Tukad Cepung, untuk di bagian bawah yaitu pada lokasi air terjun secara umum merupakan daerah aliran sungai, tanah yang berada di skitar aliran sungai merupakan tanah timbul bekas bendungan terdahulu, di sisi kanan dan kirinya merupakan lereng terjal dengan kemiringan antara 80-90ㅜ, kemudian untuk dibagian atas yaitu tempat parkir dan loket secara umum merupakan lahan persawahan dan kawasan sakral berupa pura dan setra. 


\subsection{Kondisi Eksisting Rekreasi Wisata Alam Air Terjun Tukad Cepung}

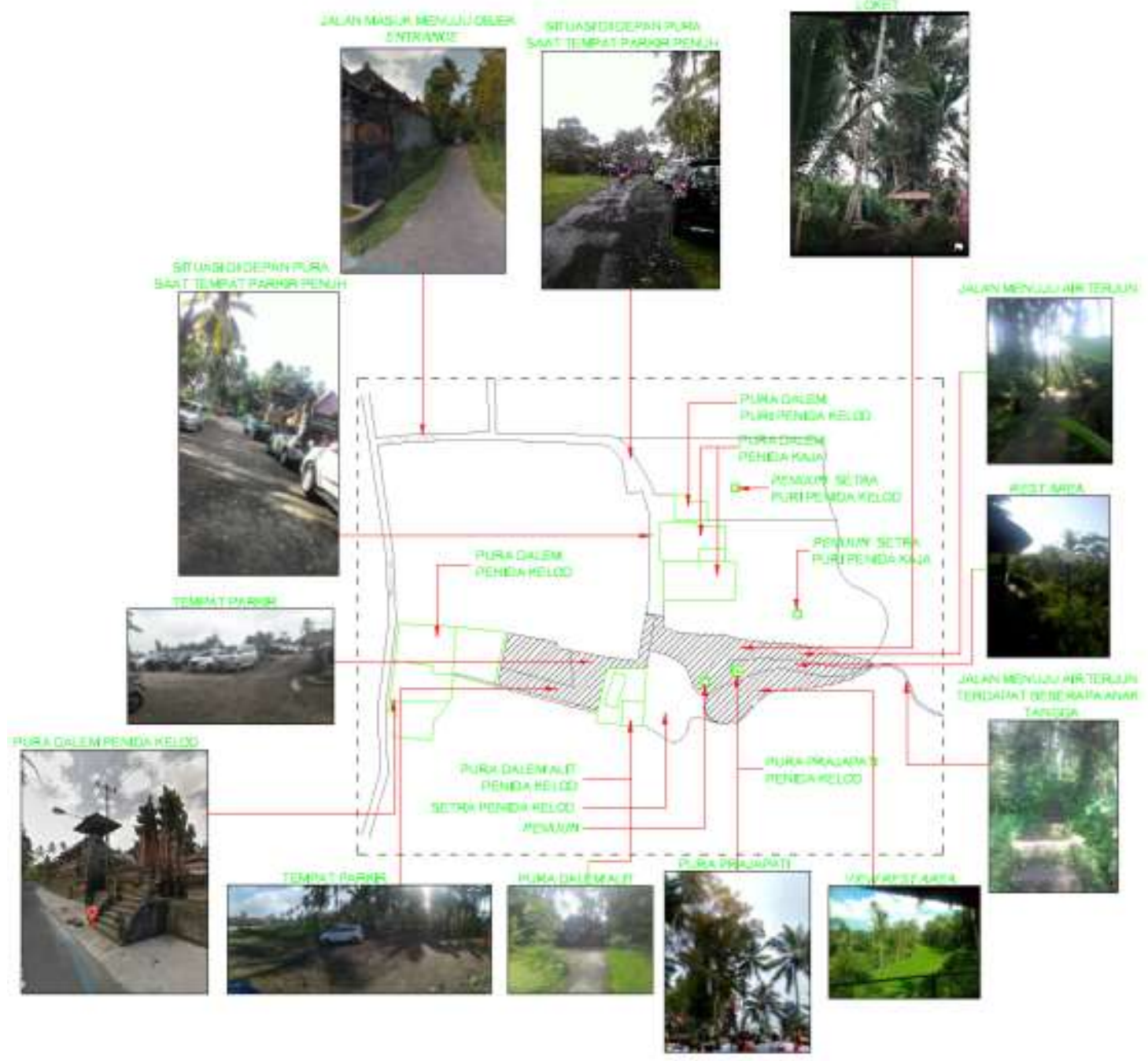

Gambar 2. Kondisi Eksisting Site Atas Objek Wisata Tukad Cepung (Sumber : Dokumentasi Pribadi)

\section{a.Zoning}

Kelompok ruang utama merupakan fasilitas utama bagi pengunjung yaitu outbond, air terjun, camping camp, wisata religi, wisata agro. Zona kelompok ruang penunjang yaitu ruang pengelola, shouvenir shop, loket, loker, pusat informasi, cafetaria. Zona kelompok ruang servis seperti parkir, pos jaga, gudang.

\section{a. Massa Bangunan}

Building Form and massing menurut Shirvani (1985) ialah membahas mengenai bagaimana bentuk dan massa-massa bangunan yang ada dapat membentuk suatu kota serta bagaimana hubungan antar massa yang ada. Pada penataan suatu kota, bentuk dan hubungan antara massa seperti ketinggian bangunan, pengaturan massa bangunan dan lain-lain haru diperhatikan sehingga ruang yang terbentuk teratur, mempunyai garis langit yang dinamis serta menghindari adanya lost space (ruang tidak terpakai). 


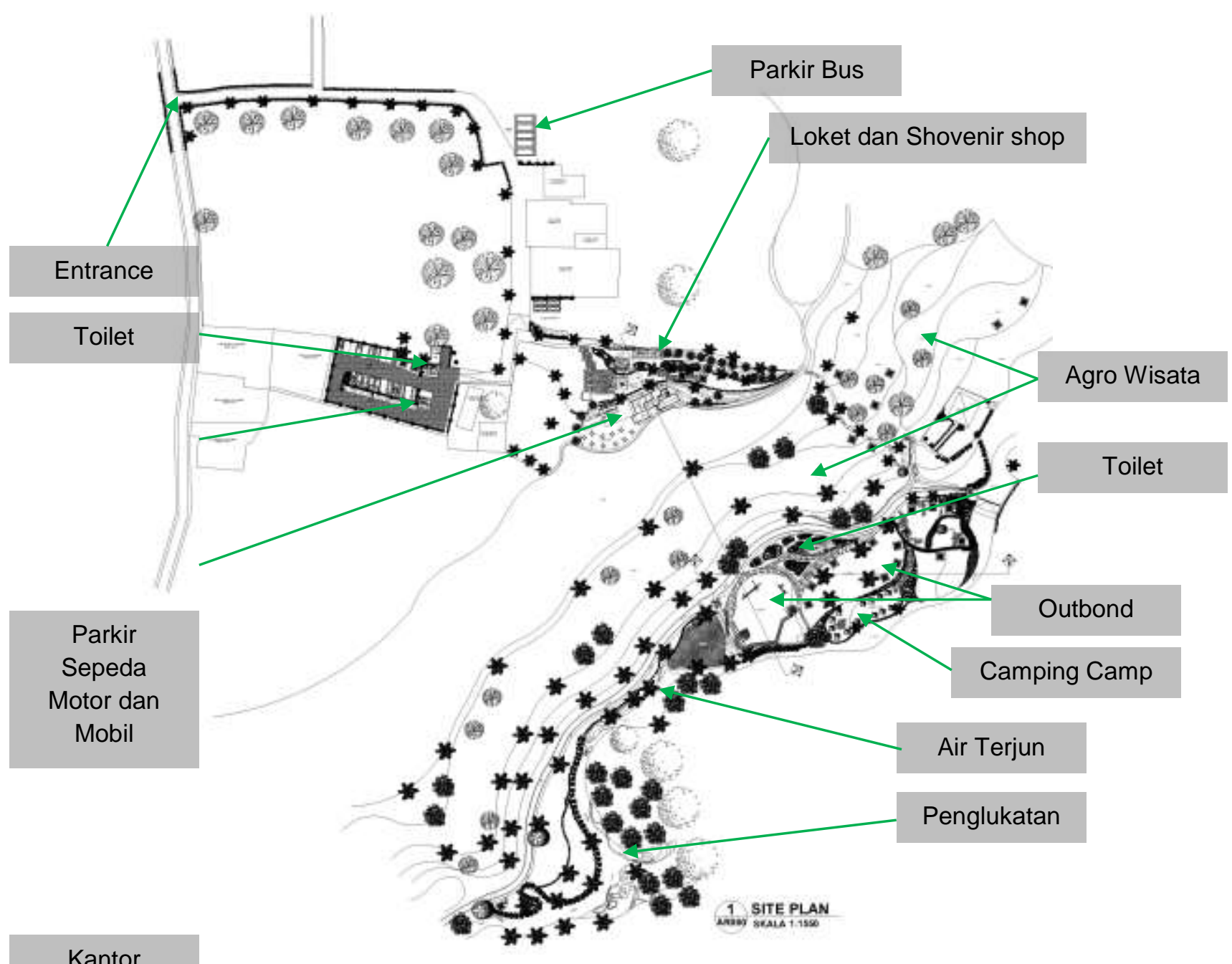

Pengelola

dan Cafetaria

Gambar 3. Bentuk dan Massa Bangunan

(Sumber : analisis pribadi)

\section{c. Konsep Pola Parkir}

Tujuan penentuan konsep parkir adalah

tukan perletakan dan pola parkir yang sesuai dengan kebutuhan, baik parkir untuk pengunjung dan pengelola. Area parkir yang dirancang pada tapak dibedakan menjadi tempat parkir mobil, bus, dan sepeda motor. Parkir pengunjung dan pengelola tidak dibuat terpisah. Sedangkan untuk kendaraan servis berupa mobil barang tidak tersedia karena disesuaikan dengan fungsi kendaraan yang hanya datang membawa dan meletakkan lalu pergi.

\section{d. Jalur Pejalan Kaki (Pedestrian Ways)}

Untuk jalur pejalan kaki diberi pembedaan level dan material untuk menegaskan area parkir. Jalur sirkulasi kendaraan menggunakan grass block. Level jalur pedestrian 


\section{Jurnal AM MALA}

Volume 9, No. 1 | Februari 2021

dibuat lebih tinggi dari level area parkir dan jalur sirkulasi kendaraan, untuk jalur pejalan kaki menggunakan paving block.

\section{e. Ruang Terbuka (Open Space)}

Ruang terbuka hijau di objek wisata air terjun tukad cepung merupakan ruang terbuka hijau alami yang akan ditata dengan penambahan vegetasi serta perubahan bentuk landscape pada kawasan sesuai dengan fungsinya.

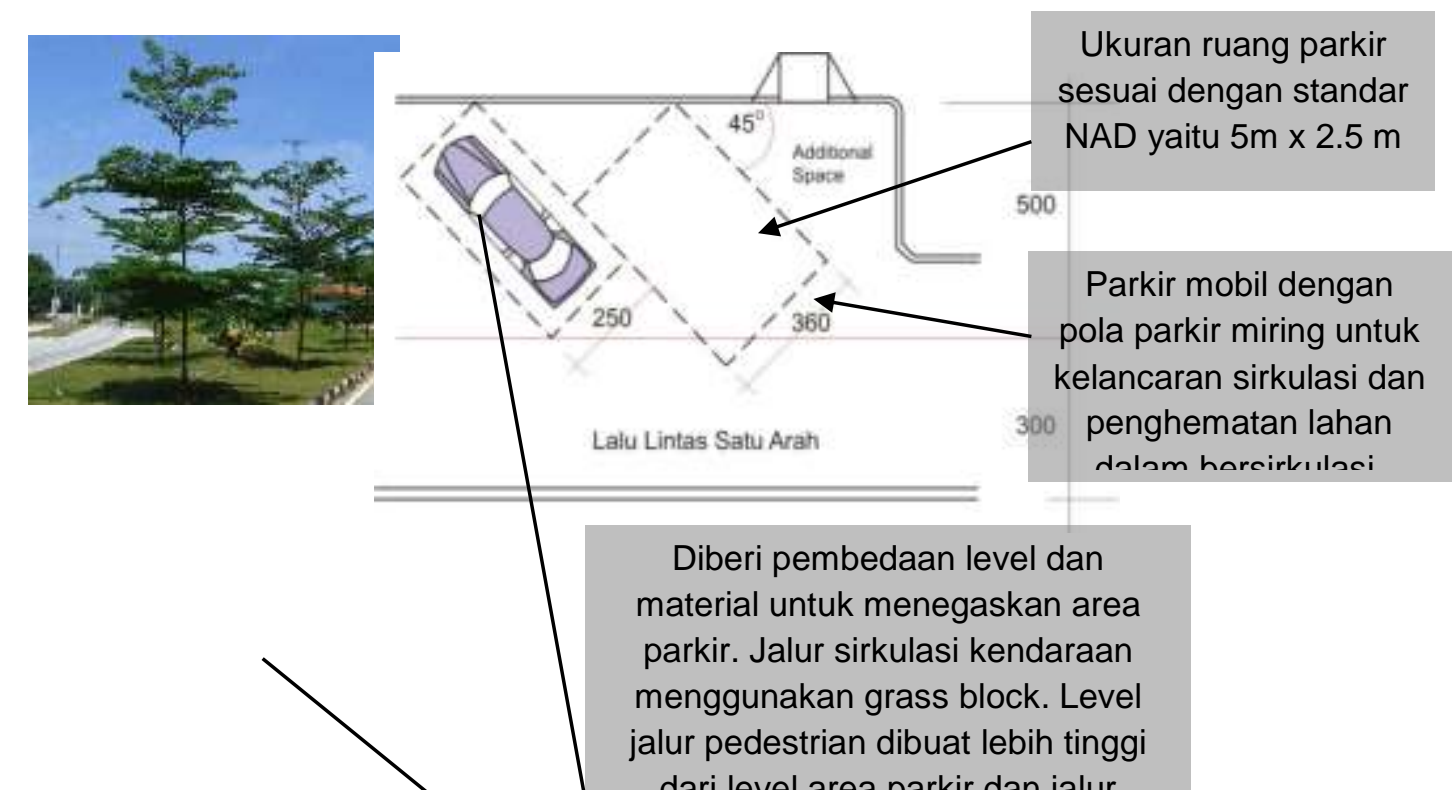

Pohon Ketapang

Kencana dengan tajuk mencapai 3

Digunakan pola parkir lurus bagi kendaraan roda 2 (dua) untuk menqhemat lahan. dari level arga parkir dan jalur

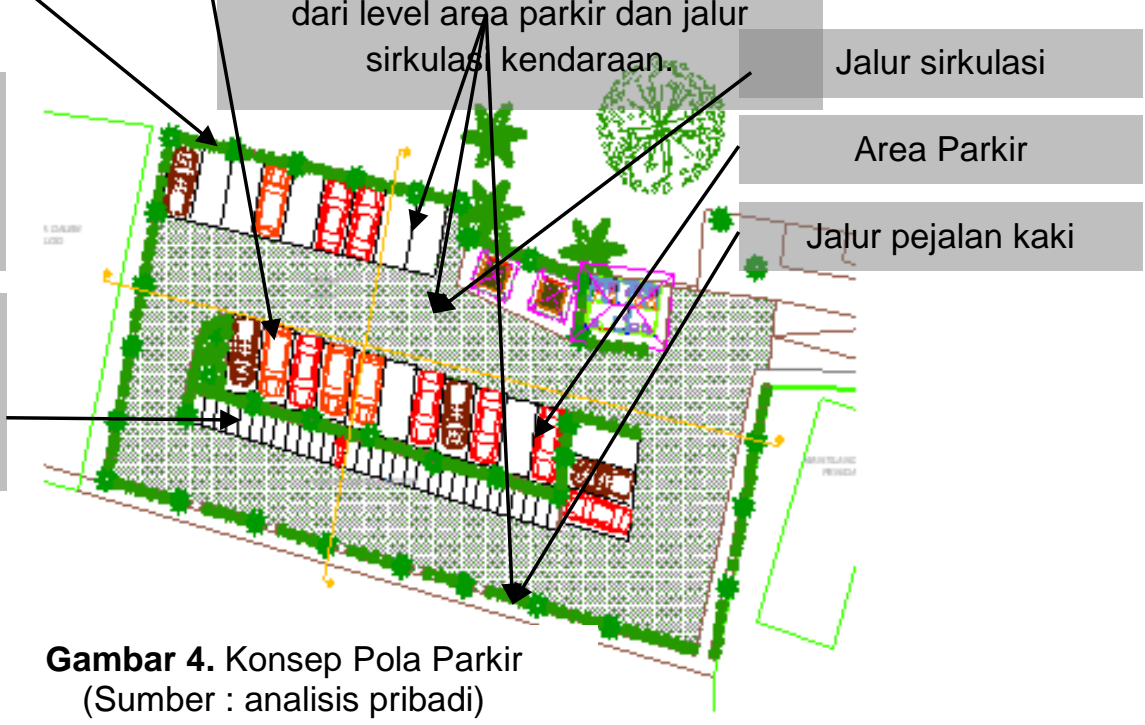

\section{d. Jalur Pejalan Kaki (Pedestrian Ways)}

Untuk jalur pejalan kaki diberi pembedaan level dan material untuk menegaskan area parkir. Jalur sirkulasi kendaraan menggunakan grass block. Level jalur pedestrian dibuat lebih tinggi dari level area parkir dan jalur sirkulasi kendaraan, untuk jalur pejalan kaki menggunakan paving block. 
e. Ruang Terbuka (Open Space)

Ruang terbuka hijau di objek wisata air terjun tukad cepung merupakan ruang terbuka hijau alami yang akan ditata dengan penambahan vegetasi serta perubahan bentuk landscape pada kawasan sesuai dengan fungsinya.

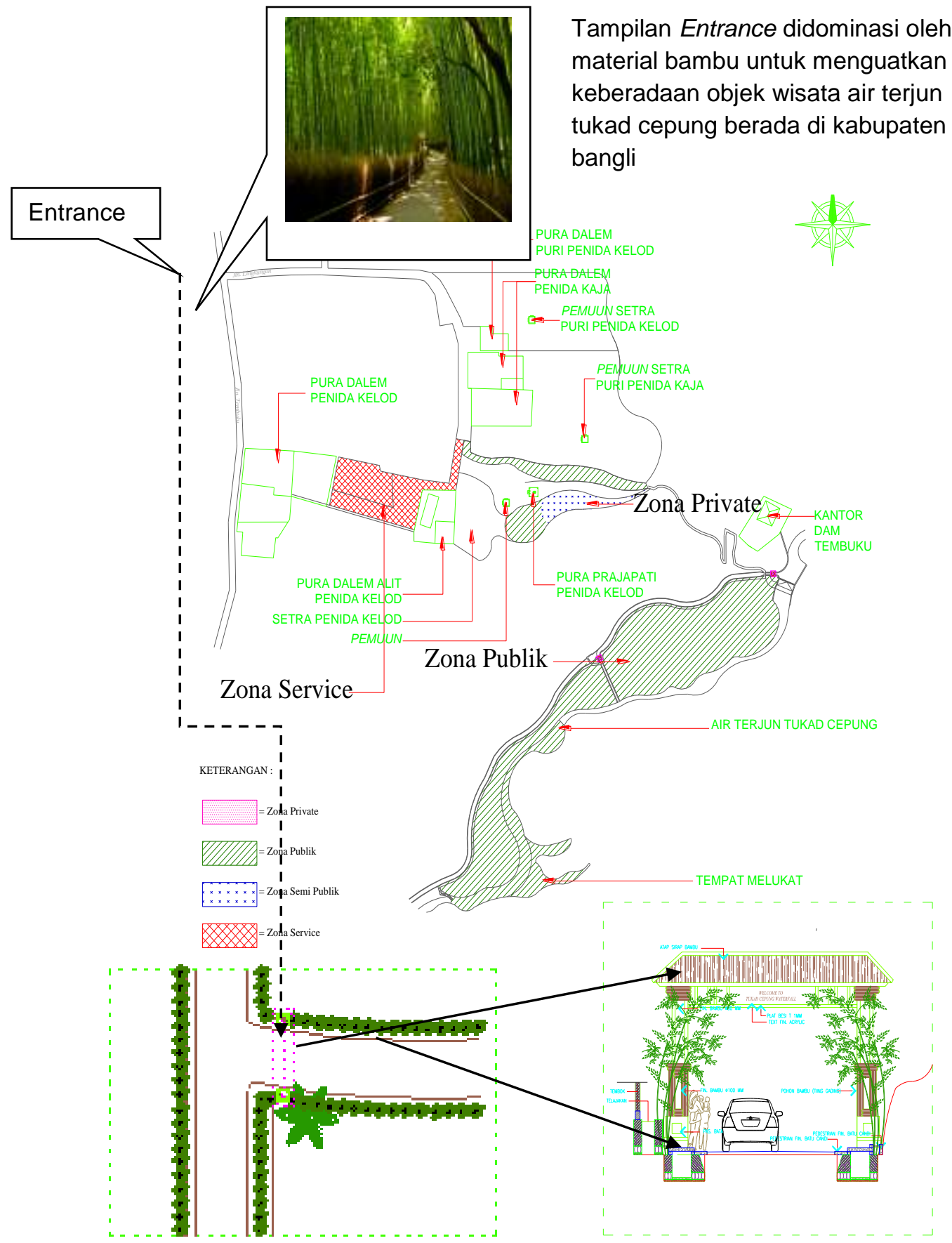

Tampilan Entrance harus memiliki daya tarik dan mampu memberikan nuansa etnik/ arsitektur tradisional yang khas. Bentuk angkul-angkul

Gambar 5. Konsep Entrance mengadopsi gaya arsitektur desa tradisional bali penglipuran (Sumber : Analisis Pribadi) 
Volume 9, No. 1 | Februari 2021

\section{f. Penanda (Signage)}

Akses jalan menuju lokasi tapak hanya ada 1 (satu) yaitu pada jalan utama Jalan Tembuku. Dimensi jalan utama memiliki lebar $4 \mathrm{~m}$ dan dalam perancanagan tempat rekreasi ini, sesuai dengan kondisi site maka entrance keluar dan entrance masuk dijadikan satu.
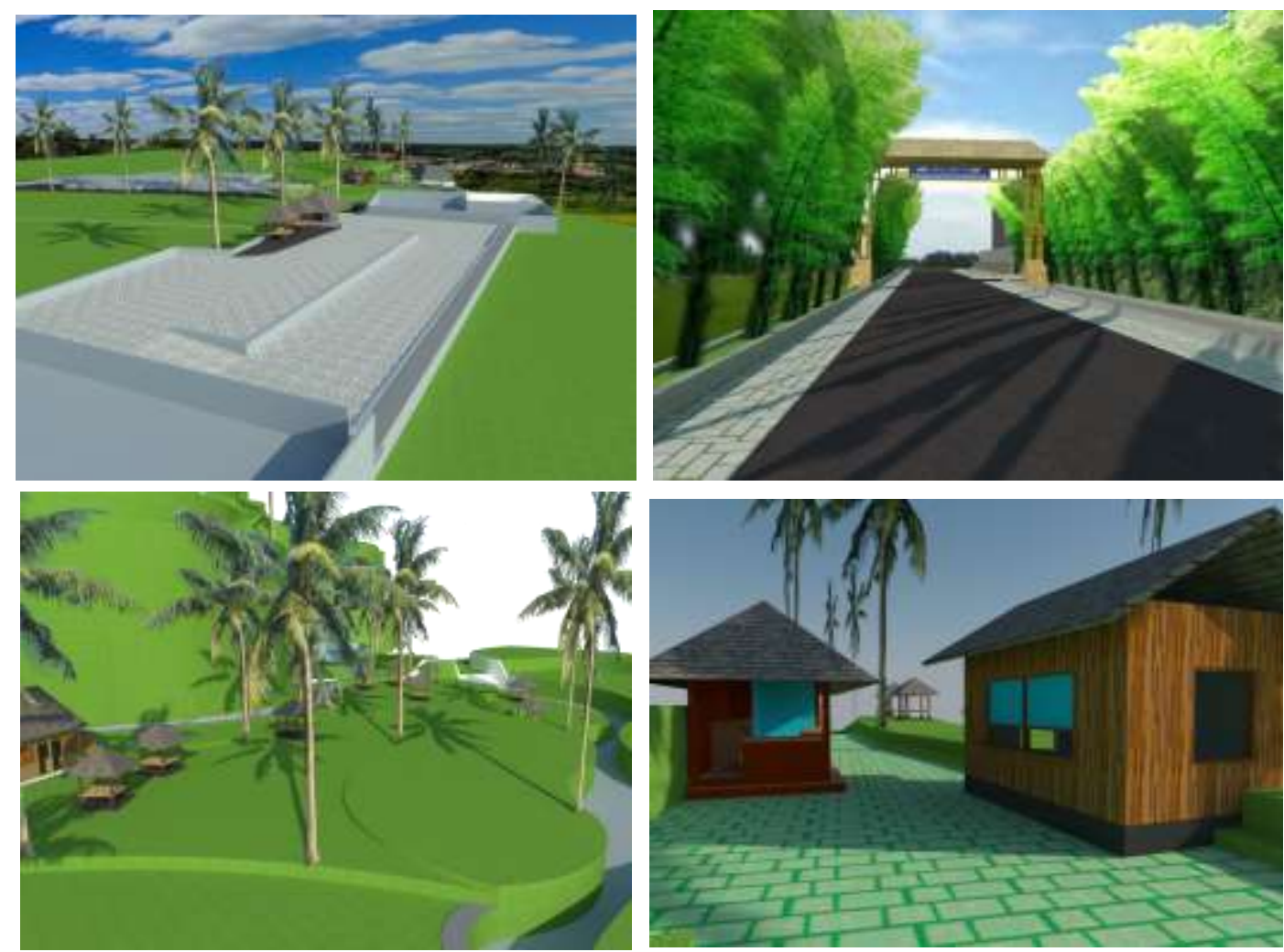

Gambar 5. Tampilan Perspektif

(Sumber : Analisis Pribadi)

\section{PENUTUP}

\section{Simpulan}

Dari hasil kajian literatur dan faktual serta hasil analisis maka dapat disimpulkan beberapa hal tentang Pengembangan dan Penataan Rekreasi Wisata Alam Air Terjun Tukad Cepung yaitu:

1. Pengembangan dan Penataan Rekreasi Wisata Alam Air Terjun Tukad Cepung ini memuat 8 (delapan) elemen perancangan kota sebagai pedoman dalam merancang sebuah kota yaitu: Land Use, Building From and Massing, Circulation and Parking, Open Space, Pedestrian Ways, Activity Support, Signage, Preservation.

2. Memiliki 4 konsep penzoningan yaitu zona servis, zona public, zona semi publik, dan zona privat.

3. Dalam Pengembangan dan Penataan Rekreasi Wisata Alam Air Terjun Tukad Cepung ini dengan konsep Green Architecture, Green Architecture atau Arsitektur Hijau adalah arsitektur yang minim mengonsumsi sumber daya alam, ternasuk energi, air, dan material, serta tidak menimbulkan dampak negatif bagi lingkungan. 
Saran

Diperlukannya penataan lebih lanjut terhadap kawasan di sekitar Rekreasi Wisata Alam Air Terjun Tukad Cepung terkait perkembangan dunia pariwisata yang begitu cepat, dan ketat dan cendrung bersaing sehingga penataan berkelanjutan ini dapat menjadi penyangga dan dapat menjaga kesetabilan perkembangan pariwisata di kawasan tersebut khususnya di Desa Tembuku.

\section{DAFTAR PUSTAKA}

Bappeda Kabupaten Bangli. 2013-2033. Rencana Tata Ruang Wilayah Kabupaten Bangli. Bangli

Ching, Francis DK. 1991. Arsitektur Bentuk, Ruang dan Susunnya. Jakarta: Erlangga

DISBUDPAR Kabupaten Bangli. 2007-2018. Jumlah Kunjungan Wisatawan Ke Kabupaten Bangli. Bangli: DISBUDPAR.

Desa Pakraman Penida Kelod. 2016. ADRT Air Terjun Tukad Cepung. Penida Kelod.

Lothar A.Kreck. Yoeti. 1996, Pengantar Ilmu Pariwisata. Bandung: Angkasa

Neufert, Ernst. 2002. Data Aristech. Jilid III. oxford: Blackwell.

Pengelola Air Terjun Tukad Cepung. 2016-2018. Buku tamu Air Terjun Tukad Cepung. Penida Kelod: Pengelola Air Terjun Tukad Cepung

Shirvani, Hamid. 1985. The Urban Design Process. Van Nostrand Reindhold: New York.

Sintia Dewi Wulanningrum. 2014. Elemen-elemen Pembentuk Kota yang Berpengaruh terhadap Citra Kota (Studi Kasus: Kota Lama Semarang). Volume10 : 2. Jurnal Pembangunan Wilayah dan Kota.

Sumber Wawancara :

I Ketut Joni Wismayana. Ketua Pengelola Air Terjun Tukad Cepung. 2018. Rencana Pengembangan Fasilitas Objek Wisata. Penida Kelod.

Anonim. Stastistik. (serial online). [diakses tanggal 12 april 2018]. Dari: URL: http://www.disparda.baliprov.go.id

Anonim. Kondisi Geografis. (serial online). [diakses tanggal 16 april 2018]. Dari: URL: http://www.tembuku.desa.id

Anonim. Air Terjun Tegenungan Bali. (serial online). [diakses tanggal 17 april 2018]. Dari: URL: https://tempatwisataunik.com

Anonim. Fungsi dan Peranan Taman Wisata Alam. (serial online). [diakses tanggal 29 juni 2018]. Dari: URL: http://insanpariwisata.blogspot.com

Desa Gigit. 2012. Sejarah Objek Wisata Air Terjun Gitgit. (serial online). [diakses tanggal 18 juni 2018]. Dari: URL: http://desa-gitgit.blogspot.com

Tukad cepung waterfall. (serial online). [diakses tanggal 06 april 2018]. Dari: URL: http://www.googlemaps.co.id

Peta Pulau Bali. (serial online). [diakses tanggal 06 april 2018]. Dari: URL: http://www.googleimage.co.id

Peta Kabupaten Bangli. (serial online). [diakses tanggal 06 april 2018]. Dari: URL: http://www.googleimage.co.id 